Portland State University

PDXScholar

Summer 8-1-2013

\title{
First-Generation Latinos at Pacific Northwest University: Their Adjustment and Experience during Freshman Year
}

Marco Antonio Aguirre

Portland State University

Follow this and additional works at: https://pdxscholar.library.pdx.edu/open_access_etds

Part of the Higher Education Commons, and the School Psychology Commons

Let us know how access to this document benefits you.

\section{Recommended Citation}

Aguirre, Marco Antonio, "First-Generation Latinos at Pacific Northwest University: Their Adjustment and Experience during Freshman Year" (2013). Dissertations and Theses. Paper 1025.

https://doi.org/10.15760/etd.1025

This Thesis is brought to you for free and open access. It has been accepted for inclusion in Dissertations and Theses by an authorized administrator of PDXScholar. Please contact us if we can make this document more accessible: pdxscholar@pdx.edu. 
First-Generation Latinos at Pacific Northwest University:

Their Adjustment and Experience during Freshman Year

by

Marco Aguirre

A thesis submitted in partial fulfillment of the requirements for the degree of

\author{
Master of Arts \\ in \\ Sociology
}

Thesis Committee:

Alex Stepick, Chair

José Padín

Roberto De Anda

Portland State University

2013 
(C) 2013 Marco Aguirre 


\begin{abstract}
This thesis details the lived experiences of ten first-generation Latino students at a large public university in the Pacific Northwest. Their experience and adjustment reveal that they relied on their friends and family, especially their parents for the male participants, for support and encouragement. The help these students received in the form of caring and social capital from faculty and staff during their freshman year ensured that they made a successful adjustment to college. Participants cite influential people and programs that motivated them to succeed and become comfortable in the college student role.
\end{abstract}




\section{ACKNOWLEDGEMENTS}

First and foremost I would like to thank my parents and family, without their encouragement, support, and motivation I would not be where I am today. I want to thank the participants of this research; they were kind enough to take the time to help me with my research and talk about their schooling experiences and family. I also want to thank Jena Zarza for her awesome editing skills and being a great friend throughout this long process. Also, I want to thank my committee for their support and encouragement. Dr. Stepick, Dr. Padín, and Dr. De Anda, thank you for challenging me to do my best. 


\section{TABLE OF CONTENTS}

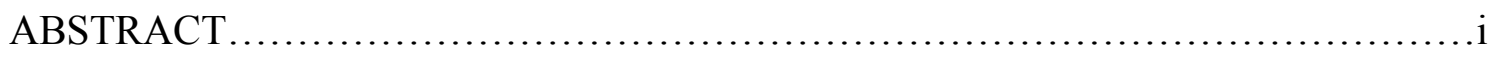

ACKNOWLEDGEMENTS ........................................................

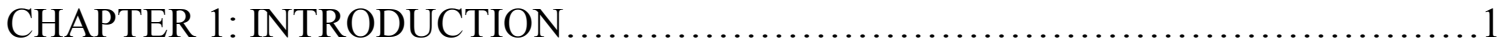

CHAPTER 2: LITERATURE REVIEW ......................................

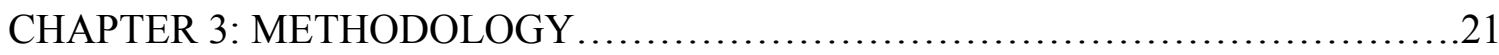

CHAPTER 4: INTERVIEW FINDINGS ..........................................

CHAPTER 5: DISCUSSION AND CONCLUSIONS.................................57

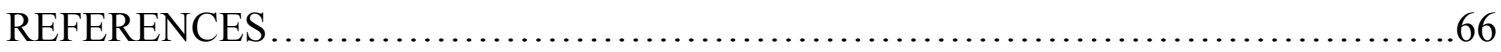

APPENDIX A: The Participants......................................... 72

APPENDIX B: Interview Guide................................................ 73 


\section{CHAPTER 1: INTRODUCTION}

This thesis addresses the question of what factors prompt Latino students, both male and female, to apply to and attend college. This question is particularly important because not only are Latinos the fastest growing ethnic group in the majority of US states (National Conference of State Legislatures, 2011), but they also have the lowest college enrollment and completion rates, i.e. compared to Blacks, Asians and whites (Perna, 2000; NCSL, 2011; Reyes and Nora, 2012). For educators, this Latino gap is important in and of itself (Bohon et al., 2006), but it has deeper implications more broadly. The earnings gap between those who have finished high school only and those who complete college continues to increase with the American Community Survey estimating that in 2011 college graduates earn 85 percent more than high school graduates (Thomas, 2012). This earnings gap is important generally, but given the especially low Latino college completion rate and the growing Latino population, determining why Latinos do or do not attend and complete college is especially important.

To address this question, this thesis focuses on a group of first-generation Latino college students at Pacific Northwest University (PNU) [a pseudonym, along with all programs and participant names]. I focus on first-generation college students, i.e. students for whom neither of their parents completed college, because most Latino college students are first-generation college students and because first-generation college students in general constitute a significant proportion of the overall college population. First-generation college students make up 47 percent of all entering college students, 53 percent of all entering students at 2-year colleges, and 34 percent of all entering students 
at 4-year universities (National Center for Education Statistics, 2005). First-generation Latino college students also face challenges adjusting to college life and have lower retention and completion rates than whites (Saunders and Serna, 2004; Perna, 2000; Stanton-Salazar and Dornbusch, 1995; Perez and McDonough, 2008; Reyes and Nora, 2012). First-generation Latino college students are likely to confront particular challenges tied to their ethnic identity. Latinos are family oriented and young Latinos accordingly are highly likely to work and have extended family obligations (Desmond and López Turley, 2009).

A Latino family that values education can make a positive impact in their children's decision to attend college, parents can be a tremendous influence in helping first-generation Latinos decide to attend college (Cerna et al., 2007; Saenz et al., 2007). Additionally, the adjustment to college for first-generation Latinos who live on campus can be especially difficult if it is their first time away from their family (Desmond and López Turley, 2009). Family is the top priority; many Latino students would often sacrifice their grades in order to provide emotional support for family members (Nappi, 2013).

I should note that I use the term Latino to refer to Hispanics, such as Mexicans, Central Americans, and others that identify as such, as well as Latinos (Bohon et al., 2006). In Spanish, Latino can refer to either males or females or both. To eliminate ambiguity, whenever I specifically mean males, I will use the phrase male Latinos, although it is grammatically redundant. And simply to have consistency, I will also use 
Latinas, although that is also grammatically redundant but should reduce confusion for those less familiar with Spanish.

After this short introductory chapter, Chapter 2 reviews the literature relevant to first-generation Latino college students, including the barriers to them attending college and the resources that assist them. In this section, following Coleman (1988) and Bourdieu and Passeron, (1977) I develop the concepts of social and cultural capital, two terms that refer to non-tangible resources that can be transformed into educational opportunities and eventually economic rewards, such as employment and income. The original research of this thesis is based on semi-structured qualitative interviews with ten Latino students at PNU, five males and five females. Chapter 3, Methodology, describes the methods in detail. Chapter 4 describes my findings and particularly the importance of social and cultural capital in encouraging first-generation Latino college students to apply, attend and complete college. My research indicates that a student's family is the most important factor, but high school teachers and counselors can be important for female Latinas. Once in college, social and cultural capital is again critical. In college, for my respondents, social and cultural capital were most likely to come from particular programs designed either for Latinos or for freshmen in general. Chapter 5 contains a discussion of the results and their implications. 


\section{CHAPTER 2: LITERATURE REVIEW}

This chapter will review the literature pertinent to first-generation college students, particularly Latinos' experience and adjustment in college. It will also examine the gender disparity that exists between female Latinas and male Latinos enrollment in higher education. I will employ and summarize the theoretical concept of capital, specifically social capital as it applies to students in general and especially firstgeneration Latinos. Additionally, the concept of authentic caring and how it applies to education will be addressed. But first, it is necessary to define and explain some key terms that will be used in this literature review.

In this thesis, the term first-generation signifies that a student's parents do not possess a four-year degree from a US institution. Generation status in this context refers to parental education and not immigration status. Also, when using the terms Latino, Latina or Chicana, these all refer to students whose ancestors are from Latin America. It was decided not to use the term Hispanic for this research because that term is not widely used among people who come from Latin American countries; that term will only be used when referencing other research that uses it. In Spanish, the term Latino refers either to both males and females or solely to males, while Latina refers specifically to females. To avoid ambiguity and confusion, I will use Latinos to mean either males or females. If I intend solely males, I will employ male Latinos or Latino males and for the sake of consistency I will use female Latinas to refer to females even if the latter is grammatically redundant.

\section{Various Forms of Capital}


The concept of social capital became popular in Sociology in the 1990s and 2000s (see Portes, 1998). The term is an extension of the earlier use in economics to refer to financial capital, i.e. money or savings. The first extension, used again primarily by economists, was human capital which refers to education and skills that yield a return in the labor market, i.e. someone with higher human capital can get a better job with higher pay or benefits. Social capital refers to the relations that exist among persons in an effort to develop human capital (Coleman, 1988). While physical capital is embodied in machines and other equipment, social capital "comes about through the changes in the relations among persons that facilitate action" (Coleman, 1988:S100). Social capital is thus utilized among persons in social relationships where those who have more social capital, i.e. know more people, are trustworthy, and are developing or possess specific knowledge (e.g. a college graduate or a teacher), are able to share their social capital with others who may be developing their own social and human capital.

Cultural capital as Bourdieu (1986) notes "is convertible, on certain conditions, into economic capital and may be institutionalized in the form of educational qualifications" (1986: 243). For Bourdieu (1986) “embodied" and "objectified” cultural capital is instilled through a child's socialization and childhood when parents expose their children to different activities such as art, music, and theatre. Children of different social classes will be exposed to different aspects of culture according to both the desires of parents and their economic capital and time to do so. While from the anthropological perspective, everyone has culture. However, from the cultural capital perspective, some cultural capital is capable of being transformed or instrumentally used to obtain economic 
ends. So, children of lower economic classes have just as much culture as children of parents who are better off, but the culture of the children of lower economic classes will not be transformable as readily or as much into economic capital. Thus, children of lower economic classes can be said to have less cultural capital, even if they have just as much culture. Bourdieu, who first coined the phrase, employs examples from the French upper classes referring to such things as manners and which forks and spoons to use at a "high class" restaurant. When applied to higher education, cultural capital can mean, for example, the knowledge of which colleges and universities are more prestigious and likely to ultimately provide a degree which gives access to better jobs. It is also reflected in mundane educational activities such as knowing how to read a syllabus, access the library, or take notes.

Within studies of Latinos and higher education, Stanton-Salazar and Dornbusch (1995) define social capital as "social relationships [from] which an individual is potentially able to derive institutional support, particularly support that includes the delivery of knowledge-based resources, for example, guidance for college admission or job advancement" (1995:119).

As mentioned earlier, capital can take many forms; in the area of education social capital and cultural capital are the two types of capital used most often to explain discrepancies and inequalities that exist among gender, race and ethnicity, and social class in education. Cultural capital is often utilized in academic research as it pertains to embodied cultural capital, that is, how a child was exposed to music, art, theatre, or other culturally enriching activities as a child (Dumais, 2002). Social capital emphasizes the 
networks and relationships that people possess rather than their social class or exposure to culturally enriching activities (Coleman, 1988).

James S. Coleman explains social capital as, "the function identified by the concept of 'social capital' is the value of these aspects of social structure to actors as resources that they can use to achieve their interests" (Coleman, 1988: S101). Coleman goes on to describe a study of the dropout rate and how it relates to the amount of time parents spent with their children. The human capital, which is the skills and education that a person possesses, is often determined by level of education. However, even if a parent is well educated, if that parent is not spending sufficient time with their children to pass on their human capital, in the form of social relations, then the child will not benefit. Additionally, even if that parent has a high level of human capital, measured by their education and skills, say a bachelor's degree, and they spend a great deal of time with their children, if the social relation is not strong between parent and child, the human capital will not be passed along to the children; this is a lack of social capital. Essentially, if there are not strong relations between children and parents "whatever human capital exists in the parents, the child does not profit from it because social capital is missing" (Coleman, 1988: S111). As this relates to children dropping out of high school, those children who come from single parent households are more likely to have a child drop out from high school due to the lack of time spent with them. Furthermore, even if a child comes from a two-parent household, if they are from a large family with many siblings or they are a younger child, their educational outcome is not a strong as if they were an only child coming from a two-parent household (Coleman, 1988). Social capital lends itself to 
the study of first-generation Latinos when it comes to their freshmen experience at college and the relations the students were able to build or not build during their freshmen year and how this affected their adjustment in college. Next, the review will turn to how social capital impacts first-generation Latinos when it comes to their college aspirations.

The literature on first-generation Latinos is unanimous that when they leave high school and enter college they do not possess the same level of social and cultural capital as whites and non-first-generation students (Perna, 2000; Stanton-Salazar and Dornbusch, 1995; Perez and McDonough, 2008). Students who do not have high levels of social and cultural capital may not see the need to enter higher education. They may begin the process of applying to colleges and not finish, or they could drop out of college their freshman year due to lack of networks and understanding of college life (Perna, 2000). Additionally, first-generation Latino students may not understand the long-term benefits that a college degree will provide them. Saunders and Serna (2004) argue that having limited access to cultural and social capital hinders the ability of Latinos to consider college, let alone begin the application process. Latino students do not develop meaningful relationships with their teachers or administrators in high school to the extent that they may utilize these connections to help them navigate the college entrance process, or even consider doing so (Saunders and Serna, 2004). Developing networks and relationships is crucial for Latino students who have limited access to this kind of social capital, because if they do not have access to some form of social or cultural capital they 
will not be able to transfer it into support, connections, involvement, and knowledge of the college entrance process (Saunders and Serna, 2004).

The argument has even been made that "social and cultural capital is as important as academic ability in the college enrollment decision" (Saunders and Serna, 2004:148).

Saunders and Serna (2004) have found that Latino students who have created new networks at college have a better opportunity of completing their four-year degree. Their study also emphasized the importance of old networks that students had established in high school as an important factor in improving their persistence in completing college. While their article focused mainly on college persistence, it was valuable in demonstrating the necessity of cultural and social capital that first-generation Latinos need not only to persist in college but also to enter the institution. Similarly, Somers et al. (2004) found that first-generation students who attend college full-time or live on campus while in college are less likely to dropout. The ability of first-generation Latino students to take advantage of old networks (in the form of teachers or counselors), social capital, and of caring individuals will improve their success at an education beyond high school (Saunders and Serna, 2004). Next, the importance of a caring relationship between student and teacher or staff in education will be examined.

In her study of Mexican immigrant and US-born youth at a Texas high school, Angela Valenzuela (1999) creates the concept "subtractive schooling," which is when teachers and administrators along with the general school culture do not embrace or include the culture of the Mexican students. In essence, the school is subtracting from students their language and culture by not including it in the school curriculum, not 
accepting their lived experiences, and often negatively judging students who speak, dress, and present themselves in any way that marks their Mexican origins. Valenzuela's work also presents what she terms, and what is of most concern to my study, the "politics of caring."

The caring literature (Noddings, 1984, 1992; Valenzuela, 1999), as it pertains to education, is concerned with aesthetic caring and authentic caring between students and teachers or staff. Aesthetic caring is what is expected of students by their teachers. Teachers expect their students to care about school enough so that they will eventually graduate. Valenzuela uses the term aesthetic caring to mean that teachers still care about student success but not to the extent that teachers build a trusting relationship with students and make them feel validated. Authentic caring emphasizes a trusting and understanding relationship between teachers and students. Valenzuela describes it as the "sustained reciprocal relationships between teachers and students as the basis for all learning" (1999: 61). The benefits of authentic caring are when a student feels validated and has a sense of competency over a subject or task. When authentic caring is absent, students may feel disconnected from school, the curriculum, and sense that they are just objects in the classroom. The relationship that exists or does not exist, or the difference between aesthetic and authentic caring, between teacher and student can affect if a student is engaged or discouraged in their potential to succeed in school.

Teachers making the effort to know students and authentically care about their success, according to Valenzuela, can be the difference between a student shunning or accepting education. Some teachers may only care about learning and student 
achievement and have no interest in forming a relationship with students. This limited, goal-oriented form of caring is aesthetic caring. On the other hand, teachers who form a bond and recognize that students need to be "addressed as whole beings" are taking part in authentic caring. Valenzuela succinctly states, "Indeed, as the logic of authentic caring dictates, a complete apprehension of the 'other' means that the material, physical, psychological, and spiritual needs of youth will guide the educational process" (1999:110). There must be trust in relationships and a true connection in order for authentic caring to be present, but when this is the case, this marks the beginning for learning to commence. Furthermore, parental involvement is another crucial factor to consider in the educational process of first-generation Latino students.

The level of parental involvement also crucially affects the decision to enroll in college, as do the peers that students associate with. In their study of parental involvement as social capital and college enrollment, Perna and Titus (2005) found that students whose parents spoke to them about college, volunteered at their school, and made contact with the school concerning their academics were more likely to enroll in college. Additionally, students whose friends were going to enroll in a 2-year college were positively associated with them enrolling in a 2-year college but negatively related to the likelihood of them enrolling in a 4-year college. As for students whose friends were going to enroll in a 4-year college, the relation is positive for them wanting to enroll in both a 2-year and 4-year institution. Furthermore, when it comes to Latinos and female Latinas enrolling in higher education, female Latinas far outnumber male Latinos; this gender gap between them will be addressed in the next section. 


\section{Importance of Gender}

Male Latinos enroll in college much less than female Latinas. Literature on the disproportionate number of female Latinas attending college compared to Latino males is unfortunately sparse in spite of the important implications of the gender gap in Latino college attendance (Saenz and Ponjuan, 2009). Saenz and Ponjuan (2009) posit several causes including, cultural norms, social disparities, and others such as not developing meaningful relationships with teachers and counselors, all of which relate to gender differences among Latinos in access to cultural and social capital. Since girls outperform boys in several aspects of schooling such as reading and writing, those boys who do not have a motivation for school may continue feeling inferior early in their schooling career. Additionally, boys are taught by society to be tough and strong; in the Latino culture this is highly emphasized and taken to a new level which further hinders Latino boys' interest in schooling since being good in school is seen as opposed to being manly (Saenz and Ponjuan, 2009). This, along with disciplinary problems, i.e. boys are far more likely than girls to be formally disciplined, adds to the likelihood that Latino boys will drop out in their high school years (Saenz and Ponjuan, 2009). Furthermore, Latino males do not develop caring and meaningful relationships and connections in high school which could help them consider entering higher education (Saenz and Ponjuan, 2009). Zarate and Gallimore (2005) found that Latina high school students who developed relationships with teachers and counselors was related more to their college-enrollment than to other predictors such as parental expectations and academic achievement. In other words, for female Latinas, social capital plays a bigger role than what their parents expect of them 
academically. Additionally, there is a long list of factors that are hindering Latinos from entering college. These factors include obtaining employment to provide for their family and other financial constraints that may prevent them from considering furthering their education beyond high school.

The growing number of Latino males who are entering the workforce also impedes them from continuing into higher education. In Latino culture, the male is expected to be the breadwinner in the family. Even if he does not have a family of his own, the Latino male is almost expected to provide financially to his natal family, i.e. the family that raised him (Saenz and Ponjuan, 2009). This cultural aspect leads Latinos to find work when they are young with relatively little education, often not requiring a high school diploma. Accordingly, that work is usually labor intensive and likely low paying. Saenz and Ponjuan (2009) have indicated that the gender roles of Latinos place female Latinas in the home and male Latinos in the paid workforce. Although this is not always the case, it is dominant in the Latin culture. There is an implication of various factors that affect the outcome of whether Latino males will attend college; among them are parents, teachers, and counselors. These agents and the relationships or social capital that students have with them are important in determining college-enrollment for both Latinos and female Latinas (Zarate and Gallimore, 2005). Concerning the role of parental expectations and influence when it comes to female Latinas, or Chicanas, Ceja's (2004) findings seem contrary to those of Zarate and Gillamore (2005) who claim that social capital plays a bigger role than parent's expectations. 
In his study of the role of parents and "Chicanas"” college aspirations, Miguel Ceja (2004) states that first-generation female Latinas are motivated to attend college by listening to their parents' stories, seeing them work hard, and knowing they, the parents, did not receive a sufficient education. While a student's parents may not have directly mentioned anything pertaining to college or obtaining a higher education, the 20 female Latinas in Ceja's study were all able to decipher the messages that their parents would relay to them. When the parents of these female Latinas would speak to them about doing well in school and getting good grades, they never explicitly mentioned the word college. Through the lived experiences of their parents, the female Latinas saw and understood they needed to do their best and work towards the educational opportunities that are available to them which their parents might not have had when they were growing up.

Ceja (2004) says that this resiliency of "Chicanas" to do well in school and want to further their education beyond high school stems from their parents reinforcing the notion that without an education they will not be able to get a high-paying job. Additionally, hearing the messages of support and encouragement from their parents helped these female Latinas to realize that they wanted to go to college so they would not have to work low-wage and labor intensive jobs like their parents. This was a common theme for the female Latinas; they wanted to improve their economic standing. For many of them, seeing how their parents worked long hours for minimal pay, along with realizing they have opportunities their parents did not, was another reason to do well in school and go to college. The relationship with parents is only one factor to consider 
when addressing the gender gap between the higher enrollments of female Latinas in college compared to Latinos.

In her analysis of why more Hispanic and white females attend college than their male counterparts, Riegle-Crumb (2010) argues females possess more social capital than males. In particular she indicates females have greater involvement and interaction with peers, school officials such as counselors, and parents. "Hispanic" females (or female Latinas) are specifically more likely to believe that achieving a higher education is a vital way of having a better future and they are better prepared academically in high school than Hispanic males (Crosnoe et al. 2004; Gándara, 2005; López, 2003; Mead, 2006; Saenz and Ponjuan, 2009). Although Hispanic females may be better prepared academically and want to achieve a better life through attending a university, they may not always realize this goal due to financial constraints and family obligations (Sy, 2006). It could be that the gender differences in academic preparation are a vital reason that more Hispanic girls are attending college than males. This also signals the perseverance of Hispanic females to overcome hardship and attain a higher education (Barajas and Pierce, 2001). Hispanic females are seen to rely heavily on their friends for support academically than their male counterparts, and female Latinas are also more likely to have a strong relationship with their parents and be closer to school officials (Barajas and Pierce, 2001).

Riegle-Crumb (2010) notes that minority youth may be the most necessary recipients of social capital for the benefit of their education in the long-term. This is especially the case with regard to relationships with school personnel such as counselors 
and teachers who can help develop the skills and offer the knowledge necessary for minorities to apply and realize the importance of college. A majority of minorities are likely to be first-generation students and they could benefit from the social capital embodied by school agents. The relationship with school personnel could also explain the gender gap that exists between females and males of all races and ethnicities when it comes to college attendance, but more so for Hispanic youth. Although a relationship may exist between Hispanic students and their peers and parents, it is necessary for those agents to have specific knowledge of college in order for the social capital to have any useful potential. If Hispanic students cannot turn their relationships with others into social capital that will benefit them academically then this may diminish their chances of attending college.

From her results, Riegle-Crumb finds that Hispanics are less likely to attend college than whites but that Hispanic females are more likely to attend college than Hispanic males. There are also gender differences in courses taken, such as Advanced Placement (AP) or International Baccalaureate (IB) courses. Females also report spending more time conducting homework outside of school than males and have higher expectations for receiving good grades. Also, Hispanic and white females reported being friends with those who are more academically focused than their male counterparts; and females also reported speaking about college to their counselors more than males; finally, the females also reported having a closer relationship to their parents than the male participants. This is an interesting finding considering that Hispanic males are also close to their family. Many Latinos, both male and female, live at home in the Latin culture 
well beyond their eighteenth birthday. It is not uncommon for Latinos to live with their parents even when they are married as a way to consolidate resources and repay their parents by taking care of them in their elder years.

Another factor to consider with Latinos is whether they live at home while attending college. The role of familism, or the close ties between kin that Latinos share when it comes to decision making where the individual is second to the group, is seen to be overwhelmingly positive when it comes to educational outcomes (Desmond and López Turley, 2009). When it comes to living at home for college, it may seem an easy decision for Latinos because they do not have to think about having to pay for rent, utilities, and food, in addition to their tuition and fees. However, there are also downsides when it comes to living with parents while attending college, among them is the loss of independence one gains while living on their own and dealing with family obligations and responsibilities such as caring for family members, which could take them away from their studies (Desmond and López Turley, 2009; Sy, 2006). Additionally, a student's decision to live at home while attending college could hinder their applying or attending a prestigious out of state institution or from applying to college at all (Turley, 2006).

When it comes to Hispanics enrolling in college, their parents' education has less to do with their decision than for African Americans (Perna, 2000). The enrollment level of Hispanics compared to whites is lower due to the lower level of the types of capital necessary when applying for college, such as social capital (Perna, 2000). When firstgeneration Latinos are enrolled in college they have overcome one hurdle but must deal 
with others, including knowing how to perform the college student role; this will be discussed in the next section.

\section{Academic Preparedness}

Many first-generation college students who are accepted and ready to attend college may not be prepared for the academic rigor required of them. Additionally, firstgeneration Latinos, who often possess less social and cultural capital than traditional students, are at a disadvantage when it comes to the tools necessary to succeed in college.

In their study of faculty expectations and how first-generation students understood those expectations, Collier and Morgan (2008) explore the differences between traditional and first-generation students. When it came to school work, time management and professors expectations, first-generation students had a more difficult time adjusting to the college environment than their traditional peers. Collier and Morgan (2008) found that first-generation students were not prepared for their new role as a college student. An example comes from one of the students in the study who claimed that professors handed out the syllabus and assumed that all students knew what it was. Also, when it came to time management, faculty wanted the students to prioritize their time so that their education was at the top of the list. But for some students, especially Latinos, family comes first as does their need to work in an effort to help their family financially. This aspect of having other commitments was noted in the Collier and Morgan (2008) study when students cited having to work and meeting family and other obligations in addition to their coursework. 
The expectations of first-generation students in the Collier and Morgan (2008) study found that they had more problems when it came to time management and prioritizing their classes. These same students also had difficulty when it came to faculty expectations; they wanted more detail and clarity when it came to assignments, taking notes, and details on what was going to be included on exams. Another difference between traditional and first-generation students was the syllabus; traditional students wanted the syllabus to be short and concise while first-generation students wanted it to be detailed. Some first-generation students, as mentioned earlier, did not understand the importance of the syllabus and the purpose that it serves for a class. When it came to the source of class related information, first-generation students received the majority of their information from the professor, especially when the professor was explaining the syllabus for the first time; traditional students would gather information from the professor or the syllabus.

Communication with the professor was another area that differed among traditional and first-generation students. Depending on how the professor spoke was an influence on whether students would go up and ask them a question or not. Two barriers existed when it came to approaching professors, one was them using words specific to their discipline and the second was professors' use of vocabulary during their lecture. Both of these can hinder and intimidate the willingness for first-generation students to approach them.

Overall, cultural and social capital plays a strong role in whether first-generation Latinos will apply to college and if they do apply and get accepted how they will adjust 
and experience their freshman year. Additionally, first-generation Latino students must be able to utilize social capital to develop relationships with their professors and peers and maintain their old networks which they developed while in high school. Male Latinos are not enrolling in college at the same rate as female Latinas because male Latinos enter the workforce earlier than female Latinas, which is partly due to the cultural norm of males materially providing for their family. When first-generation Latinos do enroll in college they must learn how to develop into the college student role. They must learn to manage their time effectively, read their syllabi with care, and be able to communicate with their professors. Additionally, Latino males must learn to develop meaningful relationships with high school teachers and counselors and later staff and professors at the university (which female Latinas benefit from), which can improve their chances at applying to college and later can help improve their freshmen adjustment and experience. All of these components are crucial to their success as a college student. 


\section{CHAPTER 3: METHODOLOGY}

The purpose of this interview study was to explore the understandings of college adjustment issues of ten first-generation Latino students' at an urban university in Portland, Oregon. In particular, the researcher focused on the following questions:

- How do first-generation (FG) Latinos at Pacific Northwest University understand their college adjustment and experience as freshman?

- How do FG Latinos describe the process that led them to be college students?

- What resources do FG Latinos identify as having been beneficial for them in their college adjustment experience?

These three research questions all pertain to the different aspects of how firstgeneration Latino college students understand their experiences adjusting to college.

The criterion for selection was first-generation status, understood as neither one of the students' parents having a four-year degree; additionally, the student must have completed their freshman year, and lastly, for the purpose of this study, Latino encompassed anyone who self-identified as Latino or Hispanic. College adjustment was seen as the acclimation for freshman Latino first-generation students.

In order to fully understand the issues from the participant's perspective, I utilized qualitative methodology. This research strategy was employed because it deals with complex issues that have been previously inadequately explored. There are few secondary datasets that addresses obstacles to completing college for Latino students. Creating a valid survey instrument for the research problem would require already 
knowing what the primary issues, both opportunities and obstacles, are. This research has identified those aspects and has done so using qualitative methods.

This approach was appropriate because exploring the understandings of these students in their own words or their "individual lived experience," (Marshall and Rossman, 2011: 93) can only be conducted through utilizing qualitative methods. While others have tried to identify issues that first-generation Latino students have faced their freshman and second years in college (Hurtado et al. 1996), they did so with a sample of Latino students who were coveted by universities across America, many of them private, because of their high "potential for academic success" (p. 140). In contrast, students who attend Pacific Northwest University come from a wide range of backgrounds and abilities.

\section{Research Design}

\section{Type of Research}

This study utilized qualitative methodology. The aim of qualitative research is to understand phenomena from the perspective of participants involved in the study. Marshall and Rossman (2011) so eloquently state, "Human actions cannot be understood unless the meaning that humans assign to them is understood" (p. 91). In order for the researcher to fully capture the understanding of first-generation Latinos' freshman adjustment and experience, the process that led them to be college students, and the resources that benefitted their adjustment, the focus was on the personal interpretation and experience of this marginalized population (Marshall and Rossman, 2011).

Interview Research 
In qualitative methods, interview research is often utilized to explore a phenomenon of interest to both the researcher and the participants. This study is no different, interview research is necessary in this study because it is the lived experience of participants that is of utmost importance. It is important for participants to know that their experience is valued and of use to the scientific community.

Of the varying techniques of interviewing, this research utilized semi-structured interviews as the sole technique for gathering data. Semi-structured interviews are uniquely suited for this study because they allow the researcher to follow a predetermined script but also allow for probes and follow up questions that may arise from participant answers (Berg, 2009). Of primary importance is addressing the phenomenon at hand from the participant's perspective, the emic perspective (Marshall and Rossman, 2011).

\section{Setting}

The research was conducted at Pacific Northwest University (a pseudonym, along with all programs and participant names), a public urban university in the Pacific Northwest. This university has a student population of approximately 27,000 , which includes both graduate and undergraduate students. As of Fall 2011, just fewer than eight percent of the undergraduate students identify as "Hispanic." The setting of the university, in an urban environment, along with the background of the participants, translates into few first-generation students living on campus. This setting was chosen because the researcher is the graduate assistant to a member of the university who teaches a college success class and also coordinates a mentoring program for first-generation 
Latino/a students; as such, access to the site and participants is made easier and relationships have been developed with both gatekeepers and students. Additionally, "Based on analysis of data from the 2005-2006, 2006 -2007, and 2007-2008 Prior Learning Survey, administered in [Pacific Northwest University] Freshman Inquiry (FRINQ) courses, approximately $48 \%$ of freshmen in each year's cohort were firstgeneration students. While there is only incomplete information on the percentage of first generation students among [PNU] transfer students, nationally 53\% of all incoming community college students are first generation. Because each year, approximately two thirds of all incoming students are transfer students, it is reasonable to suggest that at least $50 \%$ of [PNU] undergraduates are first generation students" (Collier et al., 2008).

\section{Participants}

The study participants consisted of ten first-generation Latino/a freshman students from Pacific Northwest University. All ten of these students are from a college success class that specifically serves first-generation Latino students. Five of the participants were male and the other five were female. The decision to have an equal number from each gender is based on the literature that indicated more female Latinas than Latino males are attending college (Saenz and Ponjuan, 2009).

To examine a qualitative issue, such as the freshman experience of firstgeneration Latinos, I utilized a theoretical, convenience sample. Since the researcher knows the students from their college success course and feels confident that rapport and trust has been developed with them, they were chosen to participate in this study. The sample is theoretical in that both males and females were selected due to previous 
research indicating significant differences between them (Cammarota, 2004; Saenz and Ponjuan, 2009). It is a convenience sample in that ten first-generation Latinos from a PNU college success class were chosen due to accessibility by the researcher.

The students who were part of the college success class are part of a program at Pacific Northwest University, the ¡Éxito! Program, which is aimed at recruiting Latino/a students. In order for students to be considered for the program, they need to be firstgeneration (neither parent having a four-year degree), have submitted an application to the program along with an essay portion, and have applied to attend PNU. The students must also meet the requirements of the University such as a minimum 2.0 GPA, among other things. Students were selected by a committee based upon the strength of their application and accompanying essay. The program itself aims to retain first-generation students by providing some financial support, general advising, providing knowledge and tools for success, and a community support system.

Out of a potential pool of thirty-two students from the college success course, ten were chosen based upon their willingness to participate in the study. The researcher emailed approximately twenty-five of the college success course students, of the thirty-two original students these were the twenty-five whose e-mail address was known. From this point on, the researcher recruited students based upon their response to the original e-mail that was sent, which was an introductory script and an e-mail attachment that included the cover letter for informed consent, which was reviewed and approved by the institution's Institutional Review Board (IRB). 
The majority of the Latino/a students in this study are all from the urban metropolitan area with the exception of a few who are from the state but live approximately forty-five minutes to an hour away from Pacific Northwest University. Seven of the ten students interviewed are living at home and commute to school, while three participants, one male and two female, lived in on-campus housing at PNU (see Appendix A).

Subject interviews were conducted during the summer and fall of 2012. Nine of the ten interviews were held in a private office at Pacific Northwest University, each participant was interviewed separately. One interview was conducted at the university but in a cafeteria setting where there was limited noise and minimal people. There were no more than two interviews conducted in any one day. It took the researcher approximately three months to conduct all ten interviews.

During the beginning of the research, the majority of interviews were conducted with males, who were the first to respond to the researcher's e-mails. Only one female interview had been conducted before the beginning of the 2012-2013 school year, which began in late September. Once the school year began, the final four interviews with females were conducted. This obstacle of obtaining females to participate was overcome when the researcher would see them on campus and ask them whether or not they had received an e-mail concerning the study, if they had not, the researcher would obtain their e-mail account most frequently checked, which might have been different from their student e-mail assigned to them by the university. If the females encountered on campus 
had received an e-mail concerning the study, the researcher asked if they were willing to participate; the willing female students were then scheduled to participate in the study.

The interviewer adhered to the interview script during each interview but also utilized probes when necessary and asked follow up questions when clarification was needed. As the researcher was the primary instrument for gathering and analyzing data in this study, it was important for the researcher to establish a welcoming and trusting environment for the participants. Prior to the interview, the researcher would inquire about the student's summer or school term, among other things; this conversation was to establish a level of rapport and comfort for the study participants. Allowing the participants to feel at ease and comfortable was an important aspect before each interview, as it helped relax the mood before the tape recorder was turned on and the interview script was used. Once the interview began, the researcher would ask participants to give verbal consent to be audio recorded. Each interview was recorded utilizing a digital audio recorder. The average interview lasted from thirty to forty-five minutes in length. The researcher transcribed verbatim all ten interviews for analysis.

\section{Data Collection and Analysis}

The researcher was the primary instrument for collecting and analyzing data in this study. I conducted open-coding (Strauss and Corbin, 1998) on the interview transcripts. This includes reading the data, or transcripts, multiple times in order to familiarize myself with it. Then I highlighted salient quotes and came to recognize similarities and differences between the students and also the gender differences. I then began to note the recurring ideas, concepts, and opinions. My next step was to conduct 
axial coding (Charmaz, 2006; Strauss and Corbin, 1998) where I began to make connections between categories and subcategories, in an effort to solidify the main concepts. When key concepts began to emerge, I searched for common concepts and began to identify certain themes. As similar categories were collapsed and dominant themes emerged, I further examined the similarities and differences among the interview transcripts.

\section{Limitations}

While this research was meant to identify the experience and adjustment of firstgeneration Latino/a students at an urban university, the results are not meant to be generalized to all first-generation Latino students. Although this research may not be transferable to all universities, it could be transferable to other four-year public universities with similar student populations. Results of this study could be transferable given the urban characteristics of another university and similar numbers of students. Also, given that this study was conducted at a single point in time, the results of this study may not be transferable due to the fact that students' adjustment issues might change over time or new issues might develop over time that were not perceived as issues when this study was conducted.

Finally, my personal vested interest in this research is both a limitation and a strength; it is also something that I was cognizant of throughout this project. I am also a first-generation Latino college student who has experienced much of what these students have described in their interviews. Although I share this commonality with the participants, it was important for me to remember that it is the view and experience of the 
participants that needs to be showcased. I also recognize that throughout this project, my background as a first-generation Latino student will have some impact on the responses given, the analyses, and the conclusions made in this research. However, it is my background that allowed me to gain access to this population and to be able to develop the trust and rapport necessary to accomplish what I might not have been able to do, had I not shared this commonality with participants. 


\section{CHAPTER 4: INTERVIEW FINDINGS}

Consistent with prior research on first-generation students (Ceja, 2004), this study found that male and female Latino students adjusted well to college when they had the support of peers and family members. Some students required additional support that came in the form of an advisor or connection with a teacher who looked out for students and made them feel welcome; this echoes a phenomenon Valenzuela coined "authentic caring" (1999). In general, students mentioned the support and motivation of parents, friends, and family as reasons they attended college and reasons for their success in their freshman year of college.

The following topics were discussed by students across all interviews: motivation; the importance of family and parents; a lack of preparation for college coursework; and the perceived reasons behind the disparity between Latinos and female Latinas in higher education. The major differences between males and females were: the greater importance to male Latinos of living close to home, and the more motivation and encouragement needed to attend college that female Latinas received.

\section{Motivation}

Parents played a key role in motivating their child to attend college. A majority of participants, both male and female, credit their parents for encouraging and motivating them to attend college. Although female participants give recognition to their parents for encouraging them to attend college, all five females report knowing from a young age that they wanted to attend college. This certainty of attending college was not as apparent 
in the male participants who needed much more extrinsic motivation than their Latina counterparts.

Each one of the male participants specifically credited his mother, father, or other close family member with motivating them to attend college. One male student, Ramon, also cited seeing others who do not have a college education as a motivator to attend college. Ramon said that those without a college education motivate him. While they are making money now while he is struggling in college, later when he graduates, he will have what they have, such as a car and disposable income, but he will also be able to provide for his family. Being able to see college as an investment in their future was a common theme among the majority of the participants. This finding will be discussed in the section on the gender gap between Latinos in higher education.

All of the male participants spoke of how their parents would talk to them about college as a way of having a better life than they did, and a way to be able to provide for their future family. Two of the male participants, Clinton and Pancho, mentioned their fathers as the inspiration for their college aspirations. Clinton spoke about his father's willingness to pursue higher education, with the lack of funds and the need to provide for his family serving as a roadblock preventing him from doing so. He says of his father, "He didn't have education because he didn't have the means for it but that's all he ever wanted and that's why, that's another incentive of mine because it's like that's his dream and I want to achieve that for him and go to college and finish my four years and even beyond." For Clinton, going to college is not only his dream but it is fulfilling the dream 
that his father could not pursue. This is similar to the reason that Pancho decided to attend college.

Pancho was the only student in this study to attend a charter school, where he states he received personalized support from his teachers and felt more prepared for the college work than other participants in the study. Although he attended a charter school and had support and motivation from his teachers and advisors, like other males, Pancho still needed an extra push to attend college. This came from his father, who, as an immigrant, strived to attain what education he could at his local community college. Seeing his father work toward earning his GED despite a language barrier was a motivation for Pancho to go to college. He mentions his father's struggle,

Having my dad who came here as an immigrant, being a minority here, having to work extremely low paying jobs, him actually going to, there's a program he went to, a high school equivalency program, he went through that process, got his GED, he went through a nine month course at [community college], he didn't get the full education that he dreamed of but just having him as a, as an example of like 'okay man if I had all these barriers, why can't you make it, why can't you go [to college]?' Him challenging me and being that role model that he is just kind of helped motivate myself a lot more.

Pancho's father was a role model for him, and gave him that push he needed to realize that college is an opportunity of which he needed to take advantage. Pancho cites one of his friends who did not end up attending college due to financial reasons as a motivator and supporter of him attending college. While speaking of the friend who motivated him, Pancho states,

He was one of my biggest motivations, he always was there to support me. He was that older brother that I don't have. He was the one who guided me throughout the way; he was like 'you know what, hechale ganas [go forward] 
man, you can do it.' [...] Just having to surround yourself with people who care and people who want to succeed, it's a great impact on your life and especially for me, my dad and my friend, they're the biggest role models.

For Pancho, his father was an important factor in him attending college. As for the female Latinas in the study, their motivation was similar but with the difference of knowing they wanted to attend college at an earlier age than the male participants.

The female participants credit their parents as motivating and encouraging them to attend college but when asked if they knew they wanted to attend college from a young age, all of them replied that they did. This is different from the males who decided college was something that they were serious about while in high school. For the female Latinas, doing well in school was something they always knew was going to lead to bigger and better things for their future.

Samantha, a female participant who lives at home with her mother, mentions her mother as motivation to attend college. She says that she made a promise to her mother to attend college at the age of seven after watching her mother cry from the bad decisions that her older siblings made. She told her mother, "I want to be your child to go to college. [...] I told her [mother], 'I'm going to make a difference, I'm going to go to college." This sentiment of wanting to attend college at a young age is similar to that of other female Latinas.

Felicia, one of only two female Latinas to be living on campus her freshman year, says that she knew her father did not have high hopes for her two older brothers to attend college, and so she felt it was up to her to attend college. Her parents would always bring up going to college, but she did not think much about it. She says that she always had the 
option not to attend college, but she never questioned attending. Felicia says, "I obviously had that choice (to not attend college), but I just, I never questioned it, I was just like, 'I'm going to college, my parents said so.' It was just, it has to do with my parents a lot [going to college]. Being the first one to go to college is really important to me and my family. And my brothers' support is, it means a lot to me." Once again, the support of her family, and especially that of her brothers, is an important influence for Felicia, as it is for other participants. Other Latina participants also knew from an earlier age that they wanted to attend college.

From an early age, Sara and Christina both wanted to have the college experience of living on campus but were not able to do so because of financial constraints. By sixth grade, Sara realized she wanted to receive good grades because college was already on her mind. She recalls her sixth grade year, "I remember the... you know they do report cards and they're like A, B, so they categorize your level. [...] So, it was then [sixth grade] that I was like, 'Oh, okay,' you know, that's when I'm going to go to college.” Similarly, Christina says that she knew in elementary school that college was something that was going to be in her future. When asked at what age she knew she would be attending college, she recalls a conversation with her mother, "From an early age because I was just like, 'Mom, I want to go to college to be a doctor.' She's like, 'good, then you have to go to school (college).'”

Rosa, the other Latina who lived on campus, expressed a similar sentiment of attending college at an early age. The thought of attending college was not so much a question as something that she knew she was going to do. According to Rosa, her older 
sisters and her mother are intelligent women, and she felt the need to follow in the footsteps of an older sister. Both Rosa and Sara grew up hearing about college from their parents and knew it was something that they wanted to do. Similar to Pancho above, Rosa mentions her father, an undocumented immigrant, as an inspiration. Both of the participants' fathers constantly spoke about attending college. Rosa says that college "was already kind of like embedded in my mind [and] that I had to go." When she graduated from high school she received a folder of her work from elementary school through high school, and in that folder was a paper she had written in elementary school where she mentions wanting to attend college. Rosa states,

Yeah, it was in elementary school (the thought of attending college) because I remember when I graduated from high school they gave us back like a packet of all of our work that we had done over the years [...] And then I found this paper that I had done like in elementary school and I had wrote about going to college in like Salem or Portland; I wanted to be a fashion designer, which is different from what I want to do now, but it was like, I still wrote about going to college even then (in elementary school).

Knowing that she wanted to attend college at an early age, along with the support and inspiration from her family, Rosa strove to do well academically so that college would be a reality. Similar to the male participants, all Latina participants reported their parents as their motivation to attend college, and they knew at earlier ages than their male counterparts that college was going to be in their future.

\section{Influence of Parents and Family}

While both males and females credited their parents as motivation to go to college, males emphasized family more than females. Vincent, a male who lived offcampus and commuted forty minutes to school by car, said of his parents, "[...] I mean 
they were just there, they're giving you everything, your twelve years of high school, they feed you, they give you shelter and what not; so to not go to school [college] is just, not right." Another male, Clinton, mentioned his parents as an influence for him to attend college. Clinton had to commute to school by bus for approximately forty-five minutes to attend classes, and said of his parents,

I think it was definitely a factor of my parents because I feel like if my parents weren't so insistent and always there reminding me that that's the path I should take. I probably would've taken a year or two off and then, to just kind of recollect my ideas and maybe just explore a little and I think that's what their insistence and their; the fact that they were always there reminding me was why I actually took the four years and going to a four year college.

The insistence and reminders of his parents helped Clinton decide that he was going to go to college straight out of high school and attend a four-year university. Staying close to home or living at home was a factor for the male participants as well.

The majority of the males in this study did not want to stray too far from home. Attending college close to home was an important financial decision for some of them. Only one of the five males interviewed said that staying close to home was not a priority for him. This male, Vincent, said that being close to home was not an issue for him, although he did recognize the financial benefit of living at home with his parents. The other four decided to attend college close to home or to live at home while going to college. The reasons varied from their parents not wanting them to incur too much debt living away from home to a part-time job that was near where they lived at their parent's home. Clinton, the young man who travels forty-five minutes using public transportation, says that his parents wanted him to live at home. "They feel that if I'm closer to home it'll [college] be less expense on my part. I'll be saving a lot of money, which I am; I 
mean I'm debt free this year. [...] They [parents] wanted us [siblings] there [living at home] with them but also they were looking out for our best interest in the future and beyond." The theme of parental concern and family involvement is echoed by other males, and also by the parents of the female participants. When asked if staying close to home was a reason for choosing Pacific Northwest University, another male participant, Pancho, mentioned the influence of his parents in his decision to live at home, "My parents, I was, obviously I'm their first to go to college, I'm the oldest. 'We want you to stay close to home; you're not going to be paying rent.' That's another thing that, I'm not going to be paying rent; I don't pay most of the bills here [at home]. There was a lot of different things that came into play and I'm very comfortable at [Pacific Northwest University]." Attending college close to home to be able to commute to Pacific Northwest University was a smart financial decision for the male participants.

Another male participant, Esteban, cites the importance of living close to home despite living on campus. When asked if living close to home was important to him, he said,

It was, definitely was. It played a big role. I wanted to go [home], you know, since I was living off campus, off home, on campus. I wanted to go [home] at least every two weeks or at least every weekend, um because, you know, um, you work so hard throughout the week that on the weekend you just want to relax with your family and stuff. [...] So when I came to visit PNU, definitely it made a big difference that it was close to family [...].

It is evident that Clinton's, Esteban's, and Pancho's parents played a key role in persuading their sons to stay close to home. The only male living on the PNU campus his freshman year, Esteban explains why he is hesitant to be away from home for the first time. "I'm not sure how to say it, my mom; I depend a lot on my mom. So, she [has] 
always been there for me. So, in order for me to take that step (of becoming independent) I felt like, you know, she wasn't going to be there, so that's one thing I was afraid [of], too." Esteban expressed the fear of being away from his mother and becoming more independent during his freshmen year living on campus. The role of familism in the Latino culture along with financial constraints among these participants were factors in their living at home.

The female participants in the study were not as concerned when it came to staying close or living at home as the male participants. Four out of the five females interviewed did not want to stay close to home while attending college. Instead, they wanted to gain the "college experience" or get away from their hometown. A majority of the female participants wanted to live on campus, but because of financial constraints only two of the five female Latinas actually lived on the PNU campus. These young women expressed gratitude to their parents and family members for support, just like the males, but they wanted to be on their own.

Many of the colleges to which the women applied were far from their hometowns. One of the two females living on campus, Felicia, wanted to attend college in a city other than her hometown. Felicia says, "Western [Oregon University], it reminded me way too much of my hometown, and I kind of wanted to get away from that." Felicia was determined to get away from her hometown, to the extent she turned down a full ride scholarship to Boise State University. The choice of where to attend college was a difficult decision for Felicia; she had the full support of her parents, but ultimately it came down to whether or not she was going to be happy. For Felicia, part of being happy 
meant that she wanted to get away from her hometown. Wanting to get away from home to attend college was true for other female participants as well.

Another female student, Rosa, whose hometown is approximately an hour away from Pacific Northwest University, said she was not emotional about leaving her family due to living with them her entire life. Rosa said that PNU was her "dream school," but her parents wanted her to stay close to home and attend Western Oregon University (WOU). Rosa went against her parents' wishes and did not apply to WOU. "My parents really wanted me to apply for Western (WOU), and like go to Western, but I didn't want to like set myself up for that choice, to be open and just be like fine, I'll stay here in [her hometown] and live at home; so I just didn't apply for it [WOU] at all, because I did want to move out." This sentiment of wanting to move away from home was echoed by all but one of the female participants.

When mentioning where she wanted to attend college, Sara said that she wanted to keep her options open. When asked if staying close to home was a priority in selecting where to attend college, Sara replied "Not really [...] No. Because college you just, it's time for you to be independent. You want to go out there and be on your own." This was a stark difference between male and female participants of the study.

In summary, the males in this study were more concerned with staying close to home than the females. We can see a clear difference between males, who are less resistant to living at home, than the female participants, who wanted to get away from their hometowns and not have to live at home while attending college.

\section{Transition to Freshman Year}


Both female and male participants mentioned a combination of their family, friends, or an academic resource (staff or professor) as a source of support their freshman year at Pacific Northwest University. This similarity among participants shows that their college adjustment was uniformly positively impacted by the presence of people who cared about them and their schooling. For some of these students, if it had not been for a friend or one of the resources or programs on campus, they might not have progressed in their studies or even attended PNU.

While some students received support from friends and family, other participants received support from faculty or staff at PNU. Christina, one of the three female participants who live off campus, was surprised to learn the professors actually cared about students, and want them to succeed. There was a combination of things that helped Christina her freshman year. The Latino/a college success program, ¡Éxito!, her friends, and the Louis Stokes Alliance for Minority Participation (LSAMP) Program all helped Christina succeed in her freshman year of college. The LSAMP, a resource that helps students who are traditionally underrepresented in science, technology, engineering, or math (STEM) programs gave Christina the opportunity to preview a college class the summer before attending PNU. Another student, Sara, participated in a similar program called Summer Bridge.

Participating in the Summer Bridge Program, which helps introduce college life to low-income and first-generation students, helped Sara with her college adjustment. This program helped prepare Sara for college classes, but it did not help her in terms of escaping the high school mentality. Sara says students have to be more independent in 
college, which is different in high school where teachers are more involved in student success, and help is offered instead of sought after. When speaking of the differences between high school and college, she states, "In college, it's more like individually care about yourself, and you're there [in college] for your education rather than slacking off. [...] You just have to do everything on your own and you're expected to find those resources on your own, which makes it completely different [from high school]."

In addition to support at the university level, Sara also received support in high school from a federal program affiliated with Upward Bound called Educational Talent Search (ETS). The ETS Program is for first-generation and low-income students who may need tutoring, guidance in applying to college, or other services related to their success in high school and beyond. Sara claims that ETS helped her apply to colleges and walked her through the entire college application process. Once at the university, Sara credits a series of support systems, both informal and structural, that made her freshman year an enjoyable experience. She states,

Friends, and ¡Éxito! [served as support] because like, [you] have that support you know whenever I needed to talk to Diamond [program coordinator], she was there and then she just helped me with anything I needed help with or anything I needed advice with. [...] With Diamond, just having that support like I said, building that relationship or having that relationship it just makes all the difference in your college experience than those people who don't [have someone to go to for support].

This sentiment of support from the ¡Éxito! program coordinator, Diamond, was echoed by almost every participant interviewed.

Both males and females spoke enthusiastically about Diamond and the support and encouragement they received from her during their freshman year. Ramon revealed 
he might not have attended PNU if it were not for Diamond. He spoke of when he found out about the ¡Éxito! Program, “[...] and then luckily I found my guardian angel Diamond, [she] gave me a call and said, 'Hey, this is the ¡Éxito! Program.' She explained everything and I was like, now everything is going great and I'm so glad she found me because otherwise I probably would not be sitting here right now." Ramon continues his praise for ¡Éxito’s! Program director,

Diamond, it's like, you need to talk to her an hour, she'll give you two. We just need more people in this, in the educational system who are willing to care and not just because they have the degree and they have the job. [...] She's willing to listen and she, herself being Latina [...] she has so much experience that when we come to her with our problems, she's like, 'Well this is what you need to do. I this or I've done this.' She knows, she has the experience; she's just willing to help. She wants to see success in others just like she has her own success and I think that's really valuable to have that thrive for others.

For other students, having a close friend who they could confide in was their way of adjusting in their freshman year. Felicia, who lived on campus her freshman year, spoke about her friend that she went to high school with but grew closer to in the ¡Éxito! Program, "She was on my hip the whole time and then we were just like, 'We're not meeting anyone.' It was just, it was difficult but I'm glad I had her or else I probably would have gone home or something." Felicia said that it was a combination of things that helped her persist in her freshmen year at PNU. Making close friendships, learning how to manage her time from the class she took in the ¡Éxito! Program, and speaking with its coordinator all formed a support system on which Felicia could rely.

Rosa met her best friend through the ¡Éxito! Program and she credits the Program along, with Diamond, as making her freshmen year an enjoyable experience. She 
mentions that through Diamond she was able to secure a job as a mentor and that she was there for her when she needed it. Rosa gushes, "She's always there if you need anything. Or else I would have been too stressed out and had a lot of financial problems." Rosa goes as far as stating that if it were not for the ¡Éxito! Program, she would probably have gone back home to live with her parents.

In the interviews, several students mentioned their Freshman Inquiry (FRINQ) class (a requirement for all freshmen at PNU) as an enjoyable experience where they made friends. This program is part of PNU's University Studies, and must be taken for the entire year with the same professor. It also requires the student remain with the same cohort throughout the academic year. The Freshman Inquiry course could be a great way of cultivating community among freshmen students at PNU, which is also a goal of the ¡Éxito! Program.

The students who discussed their Freshmen Inquiry courses noted such things as enjoying the class, connecting with the professor more than in other classes, and/or making new friends in their class. Clinton, the student who commutes forty-five minutes to campus, spoke highly of his Freshman Inquiry class: "I really like the FRINQ class. I think that's a really good course for freshman no matter which [...] There's various ones [classes] like Globalization; I chose Race and Social Justice. I found that to be like one of the most eye opening and mind boggling experiences in classes throughout my life, in this first year of college." He went on to discuss the professor of his Freshman Inquiry course stating, "The professor was like super awesome, I just enjoyed it a lot, that class." 
This is an asset because when first-generation students can relate to their professors it makes it easier for them to communicate with them and feel they can approach them.

The professors of these Freshman Inquiry courses were praised for systematically caring about students. Ramon speaks about his Freshman Inquiry professor commenting, "[...] my professor, he cared about me because he saw potential in my writing. I actually got a scholarship through the University Studies for $\$ 1,000$ spring term because he [FRINQ professor] nominated me. [...] So, my professor was really nice to me about it [helping] and everything and willing to help me if I, for some reason, forgot to submit an assignment, he'd accept it no problem." Another male student, Pancho, reflects on having a close relationship with his Freshman Inquiry professor. He mentions getting to know this professor on a personal level, which helped him later when this professor assisted him with scholarship essays.

Felicia described how her Freshmen Inquiry course helped her adjust to PNU, and explained why the class was important to her in dealing with her initial homesickness stating, "The FRINQ definitely helped me, I was with people that were my age and we were much more than a class, we were like a community." Felicia enjoys being able to be with students who are similar in age as herself and likes that the class stays together for the entire school year rather than having a different class with new students every ten weeks. She says of her Freshmen Inquiry course, "I think it's really important, mostly freshman year to have that consistency, mostly with the whole, people living off campus and also the professor was awesome. I remember our last day of class, like a lot of us cried and stuff. We were literally a community; it was awesome." Rosa, Sara, and Felicia 
all mention that they enjoyed how their Freshmen Inquiry course lasted the entire year with the same students and that the class size was small which helped with class discussion and getting to know people. The sense of community that was developed by Freshmen Inquiry courses helped the participants adjust and have a good experience in their first year of college.

\section{Preparation for College Coursework}

Both males and females remarked on their lack of preparation for the work they encountered in college. Many students were not prepared for the amount of reading and study time required of them compared to when they were in high school. Those students who took advanced placement (AP), honors, or college preparatory courses in high school had mixed feelings when it came to whether those courses helped prepare them for college level work. Fear was a common theme amongst the participants where some students spoke about how they feared the academic challenge of college due to their senior year in high school not preparing them for what lay ahead in their college career.

Seven out of the ten participants had an academic fear of not being smart enough, failing their classes, or not being prepared for the workload; four were males and three were females. Two females admitted the fear of not being able to make friends as a fear they had when entering college. One female mentioned both not making friends and a fear of the workload in college.

As we can see, the majority of participants have an academic fear when it comes to being prepared for their college coursework. Ramon mentions not feeling smart enough when it comes to being a minority attending college. He remarks on his first day 
at PNU, "You come in [to college] knowing that you're a minority and it's like, I don't think I should be here [in college]. That came to my mind at the beginning. So coming the first day of school I'm like, 'Oh my god, I'm going to be the only Mexican.'” When asked if high school prepared him for college, Esteban responded, "I don't feel like they [high school] prepared us enough, in the sense of like writing, math, because a teacher that feels like a little bit laid back with you, when you're a senior [in high school] they [teachers] don't really push you that much." This lack of preparation in high school did not prepare students for the amount of reading required of them or their assignment load.

Many of the students were shocked with the amount of reading and work they received in college compared to high school. Christina says that she was amazed at the difference between high school and college when it came to the amount of work she receives in her classes. She had a fear that she was going to "fail everything." She says, "I really don't think high school prepared me [for college]." Students felt differently about the usefulness of higher-level courses such as advanced placement (AP) courses, when it came to preparing them for college.

Rosa mentions that she took AP courses in high school and that she was prepared for college coursework. She says, "I took AP classes and the workload was bigger [more] for that, so when I got here [to college] it [the workload] wasn't as hard." She says that the AP classes she took in high school helped prepare her for the amount of reading to expect in college. Sara on the other hand, took part in the Summer Bridge Program but still was not prepared for the difficulty and amount of work she found in college. She says, "I knew it was going to be more difficult but I didn't realize to the extent of how 
difficult, and I knew it was going to be, I knew there was going to be more work, again, I didn't realize that there was going to be a lot more work [emphasis hers]." Sara goes on to remark about the amount of reading she has received in college, "I expected there to be, like oh okay, in high school I'm reading what, a chapter and then next thing you know I'm reading two to three chapters just for next class [in college]." Sara, unlike Rosa, claims her AP course in high school did not prepare her for the amount of work that she was going to receive in college. Like Sara, Felicia noted the disparity between high school and college workloads stating,

I feel like they don't push that enough in high school because in college, like, I have older friends that are like sophomores and juniors, juniors and seniors [in college] right now, and they'd be like, you read a lot. When they meant a lot, you read a lot. Like, they [professors] expect you to read like 200 pages in like one night and that's just for one class. [...] So having like three or four main classes, like that's a lot of reading and it's a lot of time and I don't think they [teachers in high school] pushed that enough in high school.

Clinton, who also took an AP class, says that the workload he received in college was similar but that in high school the scheduling is different which makes the work cumulative. He says that he did not feel prepared academically for college. Despite an admitted lack of effort in high school, Clinton notes a noticeable difference in coursework between high school and college. Clinton's experience differs from Sara's when it comes to the perceived level of preparation their high school AP classes gave them for college. He comments on his academic fear, "A fear maybe in that perhaps I wasn't prepared academically because I feel like I slacked off a lot in high school knowing that I could do much, much better. And also because I just coming in here [to PNU] in like the first month just knowing that high school did not prepare you for 
anything [emphasis his]. There's an immense gap between high school and college even if you take AP classes." We can see that the level of preparation for college level coursework is different for the participants but some of them mention that high school did not prepare them for the workload or the reading. Next, the gender gap between female Latinas and Latinos in higher education will be addressed.

\section{The Gender Gap between Latinos in Higher Education}

The participants of this study are all from a Latin American background, sharing a similar heritage. When asked their thoughts on why there is a gender gap between female Latinas and male Latinos in higher education, where Latino males are not attending at the same rates as female Latinas, the majority of their responses were strikingly similar. They spoke of Latino males not wanting to continue their education beyond high school either because of gender stereotypes or because they want, or need, to work in order to provide for their families. The phenomenon of male Latinos working immediately after high school was brought up by male and female participants, alike. Other participants cited the Latin culture as influencing males and their decision to attend college, while others spoke of just needing self-motivation or someone to motivate them.

When the female participants were asked about the disparity between female Latinas and male Latinos in higher education, their responses included stereotypes of males and females, financial and family obligations, and female Latinas being more interested in school than their male counterparts. Three out of the five female participants, Samantha, Felicia, and Christina all mentioned stereotypes among Latinos. For Samantha and Christina it was male Latinos being involved with gangs and being 
perceived as a gangster, while Felicia mentioned male Latinos not being interested in school and wanting to drop out. Samantha states, "From what I see, it's pretty much the stereotypical Latino guy is to be a gangster, to be some sort of rapper thing or to be dealing drugs; that's what is seen on TV and that's what a lot of the Latinos are like 'that's how I need to be, that's what I need to do." This theme of stereotypes among male Latinos is echoed by Christina, who reveals about her brother, “... One of my brothers, he was involved in gangs, I guess the first thing I would be like, don't do it (join a gang), you're going to just screw up your life for it (joining a gang). What's the point? It's like, might as well go to school." Christina's experience with her brother, being part of a gang, reveals a sliver of truth behind the stereotype that Samantha and she spoke of during their interviews. Christina goes on to address another stereotype of not finishing school and how it relates to one of her brothers, “.... and then one of my brothers, he actually didn't finish high school, he didn't graduate. So, I guess that's another stereotype and that's why he didn't go (to college). And then I'd be like, 'just finish school.'...” The stereotypes of Latinos dropping out of school and being involved with gangs are reasons these female participants give for Latino males not advancing their education. The personal stories of these participants shed light on what they view in the media and their real life experiences when it comes to Latino stereotypes and Latino males not attending college.

Similar to what Christina expressed, with regard to her brother and the male Latino stereotype of not finishing or being interested in school, Felicia remarked about her brother, “And for guys, I just feel like they just don’t go to school, they skip, kind of 
like the path my brothers took (not going to college)." Felicia and Christina both have personal experiences with this gender stereotype of male Latinos not wanting to complete or further their education beyond high school. The stereotype of female Latinas getting pregnant and dropping out of school was also mentioned by some female participants.

Additional responses from the female participants as to why more female Latinas attend college than male Latinos, Samantha and Christina both mention parents being stricter with female Latinas, while other female Latinas mention that males have different thoughts after graduating from high school. For Rosa, it is her mom that drove her to attend college; she views her mother as a strong and independent woman and she wants that for herself as well. She states, "I've learned from my mom, like to do everything myself and like try my hardest and stuff and I think maybe that's the case in [with] a lot of other female Latinas. Latina moms are really hardcore." Rosa remarks about her mother being a strict and strong woman who has led by example. She goes on to say that college is more appealing, "Especially [for] Latinas because I mean, I don't think anybody really wants to be stuck in the role of like, I mean, society already says that women are weaker and stuff, I think they [female Latinas] try to get out of that by just going to college." In her case, Rosa is trying to escape the perceived notion that she is weak by going to college, working hard, and being independent; she is thinking ahead to her future and this is also what Sara mentions in her interview.

Sara describes the difference between female Latinas and male Latinos when it comes to thinking about the future. When asked about why she feels Latino males do not further their education beyond high school she states, 
I think a big part for me is like financial, I think that men, they have a different mentality than women [...] I feel like women they think more for the future. A lot of them [women], not all of them but the majority of them, they think more for the future, they're like 'okay, the future, technology is going to improve, they're (employers) [are] going to expect you to have this education, know how to do this.' Men, they're more impulsive [...] Men are more impulsive and they're just like, 'okay I did high school or I graduated from high school, that's it; I'm going to go find a job now and I'm going to support my family that way. Whereas women they're like, 'okay so, you know, in the future there gonna be a lot more jobs if I get this job in the future once I graduate, receive that [college] degree, I can support my family by making this much more money.'

Sara succinctly describes the main difference she perceives among female Latinas and male Latinos, which is that Latino males think in the short term by immediately getting a job after high school to provide for their family whereas female Latinas think ahead to the future by attaining a college degree, securing a good job, and being able to provide financially for their family.

Christina echoes the sentiments of Sara when it comes to securing a good life for her future family. She laments that school is not easy, but that it will pay off in her future. She reveals, "It'll be a good life, like my parents also [said], 'you have a better life than we did, easier, too." Christina's parents want her to have a better life and she realizes this because of living under her parents' house. She notes that female Latinas are taken care of and watched closely in the Latino culture. Christina states,

At least in my house, my parents have, I've always been the one who they're, they're always taking care of, I guess that's just in general like in every Latino home, the daughter is the daughter (she is protected and taken care of). You know, she's always on check [being monitored]. She's [her mom's] like, 'where are you at?' I'm like, 'ma, I'm right here at school.' So maybe that's why it differentiates because the guys are more free. And then culturally, the Latina girl is supposed to be by the mom, by the dad and then I guess that's why I also got the push to go to college. 
Christina mentions that Latino males have more freedom than female Latinas because female Latinas are always being monitored by their parents. This could be a reason as to why more female Latinas are pushed to attend college than their male counterparts.

Samantha also mentions that parents monitor female Latinas more closely than male Latinos. When asked why she believes that more female Latinas are attending college than male Latinos, she states, "I think it's because the parents are really strict with the girls. So, they're more, the girls are more sheltered, even though you see that a lot of the girls are getting pregnant, the Latinas. You would think that there is more males than girls [attending college] because of that." Similar to what Christina mentioned, Samantha's comments about parents being strict, especially with the females, sheds light on why she believes more female Latinas are attending college than male Latinos. For the female Latinas of this study, stereotypes of male Latinos coupled with Latino males not thinking of the future, and females being closely monitored by their parents all contribute to why more female Latinas attend college than male Latinos. The male participants shared similar views when it came to Latino males gaining employment after high school, but they also mentioned pleasing their parents as a reason for them attending college.

The Latino males of this study were also asked why Latino males do not attend college at the same rate as female Latinas. Their answers were similar to the female Latinas' answers of Latino males having to provide for their family and not being interested in school, but differed in that they specifically mentioned their parents as the motivation for them to attend college, for them to be exceptions to the stereotypes. Vincent states what some of the female Latinas mentioned above - males are not 
interested in furthering their education beyond high school. He says, "Guys (male Latinos) after school, they're like 'I'm done with high school, that's all I need; I can go out there and get a job." The inclination of Latino males entering the workforce directly after high school is echoed by other male participants.

One Latino male, Pancho, mentions that his friends from high school are always thinking about money and having to provide because they are men. He declares,

What they see (his friends) is that the financial, the financial thing is always more important. They just always see the, I personally think that, we as males have to provide $[. .$.$] So, just the fact that like we live in this world that everything is$ based off of money, we see that money is the most important thing, I mean it is but there's other things beyond it that will help and I've tried, I've explained that to them (his friends). [...] Specifically for males, like I said, they always, they want to be the provider, that's one of the things that I've talked to with Diamond as well, is like we as males feel that we need to provide, as soon as high school comes and your done with school, which is high school for them (males), they feel like they need to find a job and they need to bring money into the household and they need to provide for their younger siblings or for whatever reasons.

For Pancho's friends, having money takes precedence over having an education but they do not understand what he is trying to tell them when he states that having money is not everything in life. While Pancho agrees that a male should be the provider, he believes that gaining an education is important as well. He specifically mentions his father when asked what the difference is between him attending college and his Latino male friends from high school who did not attend. He asserts, "I think the thing that I have is my dad that he strived, got his education, I mean it wasn't the greatest, it wasn't like as far as many he wished to go, but he still got it. I think having him as my, as my engine to strive for more is the difference. [...] That's how I feel my friend's see it as, they just want everything now, in the now but not, they don't want to know how to like save it into the 
future, they just don't want to look ahead." The motivation of parents for these Latino males was a common theme as to why they decided to further their education beyond high school.

For the Latino males of this study, it seems they are trying to repay a debt to their parents for raising them as the reason they are in college. Similar to what Pancho mentioned above about his father being his "engine to strive," Esteban mentions his parents as a reason to "break the cycle and go to college." Esteban comes from an agricultural town where working in the orchards is the occupation of many families. Esteban and his friends do not want to follow in the footsteps of their hometown peers when it comes to working in the orchards, they want to break the cycle and go to college. Esteban states, “So, we didn’t want to, you know for them (parents) to feel like, 'oh, we're working this hard and now you just, out of high school and going into, uh [a] minimum wage job.' Yeah, we want it better for us and we want it better for them (parents) as well." Esteban describes that along with his friends from their agricultural community, they do not want to let their parents down after high school by not going to college and making something of their lives after their parents worked so hard to make a better life for their children. Clinton also echoed this sentiment of going to college for his parents, stating he wanted to make his father proud.

Clinton spoke about how Latino males need an influence in their life and someone to speak to them about attending college. For him it was his father, Clinton's father did not receive the education that he wanted, similar to Pancho's father, but Clinton speaks 
about his father knowing that he wanted a better future for his children. He explains about his father,

He didn't have the education because he didn't have the means for it but that's all he ever wanted and that's why, that's another incentive of mine because it's like that's his dream (to attend college) and I want to achieve that for him and go to college and finish my four years and beyond. That's my, that's another part of my incentive and I mean, that goes along with what we were talking about, sometimes it's not the parents, sometimes you just have that initiative to succeed, that hunger to be greater that what you have.

Here, Clinton mentions that he wants to attend college to fulfill his father's dream and make him proud, but beyond that he notes that sometimes it takes more than parents to want to attend college. Some children do not have parents to encourage them to attend college and Clinton remarks that they have to have an "initiative to succeed." Pancho also mentioned this in his interview, that one cannot force Latino males to attend college. $\mathrm{He}$ remarks about when he and Diamond, the coordinator for the ¡Éxito! Program, had a conversation about attending college, "I just have the strive that I want, that I have, just builds everything up, but if I was to talk to someone else (about attending college) 'you know what, this is, it's out there (college).' Just show them. Putting everything out on the table that they can have (by going to college), and it's up to them if they want to take it or not." For the male participants, there is a need to have a self-motivation to attend college, but they also had their family support, which helped them as well.

Pancho goes on to lament about the benefits of a higher education for Latino males. His response was similar to that of the female Latinas when it comes to thinking about the future. He explains, 
Just look ahead and you'll find yourself in a perfectly fine situation where you'll be able to benefit, not only you but your parents will benefit out of it (gaining an education), you're going to be helping them, well that's your choice (to help your parents) but if you're going to be there for them, they're going to be like, not only you but you're children will benefit from it; your future family will, your friends, everything will benefit from you coming to, getting a higher education, that's what I feel $[\ldots]$ look at the future.

Attending college for Pancho is not just about himself and his future but he is also thinking about helping out his parents and making a better life for his future children. This finding is similar to some of the Latina participants who thought about the future instead of the short term.

Overall, we can see that these male Latino students were able to consider college because of the support of their family and influence of their parents. The influence of parents on Latino males comes across as more apparent than for the Latina participants. Additionally, for the Latino males they did not want to let their parents down, and were able to look toward the future like their female counterparts. Looking toward the future when it comes to furthering education seems to be an important aspect for all of the participants. The reason given by the majority of the participants as to why Latino males do not attend college does not vary much between participants. The students interviewed agreed that the cultural aspect of providing for one's family takes precedence over educational goals for Latino males. Next, the implication of these findings will be discussed as they relate to the literature of first-generation Latino students and suggestions for further research will be discussed as well. 


\section{CHAPTER 5: DISCUSSION AND CONCLUSIONS}

This section summarizes the findings, placing them within previous theoretical and empirical findings. I also discuss the implications of first-generation Latino students at an urban university in terms of attracting more Latinos to enter higher education. I will conclude with a discussion of themes that need to be addressed in future research.

The major finding of this research is the critical role of support and motivation of first-generation Latino students by their parents, peers, faculty, and staff at Pacific Northwest University. Students reported that this support not only motivated them to attend college, but it also helped them overcome what they perceived as their own lack of preparation for college coursework and the adjustment to the new role of being a college student.

\section{Motivation and Caring}

The motivation to attend college for the majority of participants, and especially the males, came from their parents. This is consistent with Perna and Titus (2005) who found when parents speak to their children about college they are more likely to attend. For the males in this study, their parents, for some specifically their father, was the reason they decided to attend college. Clinton and Pancho, for example, specifically mentioned the influence their father had on their college aspirations. In chapter four, under the Motivation section, Clinton says of his father, "He didn't have education because he didn't have the means for it but that's all he ever wanted and that's why, that's another incentive of mine because it's like that's his dream and I want to achieve that for him and go to college and finish my four years and even beyond." 
The parents of female Latinas also critically influence their daughters to attend college, both in my sample and in the broader literature. According to Ceja (2004) and Zarate and Gallimore (2005) female Latinas attend college because of support, motivation, and their parents' speaking about not working labor intensive jobs. In contrast to the male Latinos, female Latinas are more likely to be motivated to attend college because they develop relationships while in high school that help them with the college application process, which is also consistent with Barajas and Pierce (2001). Female Latinas greater likelihood of developing good relationships with high school teachers and counselors means they have more social capital than male Latinos and thus a higher likelihood of applying and subsequently attending college, a finding both in my data and in Riegle-Crumb (2010). Riegle-Crumb's (2010) study also found that female Latinas are more likely to believe that possessing a college degree is crucial to a better future. For example, in my sample, Sara mentioned in her interview of getting a good job once she receives her college degree and supporting her family financially.

Latinos appear to be different from non-Hispanic whites in that their motivation to attend college is more family oriented (Saenz et al., 2007). Both male and female participants mentioned that they do not want to struggle financially, but most of them also mentioned the importance of completing college for their parents or future family. These first-generation Latino students are not just thinking about themselves, they want to achieve the dreams that their parents could not fulfill because of their legal status or need to work and support a family. This finding is consistent with Desmond and López Turley, (2009) who discuss familism in Latino culture. Familism, or the close ties 
between family members, is when individuals make decisions based upon the group or family instead of individually. These students are making a better future for their entire family and not only thinking about their individual selves.

The commitment to help one's family also appears to be related to male Latinos decreased probability of attending college. Numerous respondents, both male and female, claimed that male Latinos do not attend college because they want to earn money as soon as possible, which translates into entering the workforce full-time as soon as the males finish high school and thus not entering college. This needs to be addressed in future research. Do male Latinos who enter the workforce full-time after high school earn enough to significantly help their families? Do they earn more than female Latinas who enter the workforce immediately after high school? Is this perception that male Latinos must and can financially help their families by entering the workforce full-time after high school true? Or, is it a post hoc rationalization that explains away the male-female Latino differences in social capital acquired through high school teachers and counselors?

Social relationships play a critical role once male and female Latinos enroll in college. For the majority of participants, creating a support system, making friends, and developing caring relationships were important factors for not only deciding to attend college, but also adjusting in college, and having an enjoyable experience their freshman year. Every participant, with the exception of one male Latino in this study, Clinton, mentioned the importance of their relationship with a faculty or staff member at Pacific Northwest University. The majority of students specifically cited their relationship with Diamond, coordinator of the ¡Éxito! Program, as beneficial to their adjustment and 
experience during their freshman year. For the students, being able to talk with a Latina who holds a position of power on campus tangibly demonstrates that someone formally affiliated with the university cares about them. The relationship that many students forged with Diamond is reminiscent of Valenzuela's (1999) authentic caring. The caring nature exhibited by Diamond came in the form of listening to students, giving them advice, and building a trusting relationship with them.

As Valenzuela (1999) notes, when a student feels validated and has a sense of worth in a relationship with a teacher, they feel encouraged and a foundation for learning can commence. These Latino students felt that their instructors and staff members authentically cared for them, this lead to a blossoming relationship where trust was developed and students felt confident that they could adjust and have a positive experience in their freshman year at PNU. These students felt comfortable around Diamond, coordinator of the ¡Éxito! Program, because she authentically cares for them and she understands them culturally as well. Students felt comfortable speaking Spanish with Diamond and this helped validate the students cultural and helped develop a caring relationship between the students and Diamond.

This research has helped fill a gap in the Latino first-generation research by utilizing Valenzuela's (1999) concept of authentic caring and applying it to higher education. In Valenzuela's research she applies authentic and aesthetic caring to high school students in Texas where some were born in the United States and others were immigrants from Mexico. By applying authentic caring to higher education, the term shows potential for first-generation Latino students and the trusting and caring 
relationships they build with professors and other university agents. This research has confirmed that Valenzuela's authentic caring can be applied when looking at firstgeneration Latinos in higher education.

Furthermore, students were surprised to learn that their professors also cared about their success, which some of them were not expecting. One of the female Latinas students, Christina, was surprised to learn that her professor cared about her success. A male Latino, Ramon, spoke about how his professor nominated him for a University Studies scholarship which he was awarded. Pancho, another Latino male, also mentions becoming close with his Freshman Inquiry professor who later helped him with scholarship essays. The students who developed social capital with their professors were pleasantly surprised to learn that they cared about their success and wanted to help them in any way they could. Again, this relationship demonstrates the benefit that comes from a social relationship with professors, who possesses specific knowledge and shares that knowledge in the form of social capital with students who are trying to develop human and social capital themselves (Coleman, 1988). Additionally, many students found their Freshman Inquiry course helpful to their transition at Pacific Northwest University their freshman year.

Various students mentioned that their Freshman Inquiry course, a required course for all entering freshmen that is run by the University Studies Program, helped them make friends, build community, and exposed them to new knowledge. Felicia, one of the female Latinas who lived on campus her freshman year, expressed how she became close to her other classmates and the instructor of her Freshman Inquiry course. She noted how 
other students were similar in age and how the class stayed together the entire year, unlike her other courses. Even Clinton, who did not specifically mention a person as being influential, stated that his Freshman Inquiry course had a positive impact. Pacific Northwest University should take note of the success of this course among firstgeneration Latinos because it could be a potential tool for recruitment and retention. The solidarity, friendships, and community that were built for participants because of Freshman Inquiry are noteworthy. This finding certainly warrants further research for the University Studies Program specifically among first-generation Latino students of how a sense of community can be created and maintained for all students. Furthermore, the Freshman Inquiry courses supplied students with the cultural and social capital necessary for them to be successful students their freshman year at Pacific Northwest University. These courses accomplished this by building community for students as a year-long class that stayed together for their entire freshman year and also by helping students develop friendships with other students in their Freshman Inquiry course.

Overall these findings are consistent with prior research (Saunders and Serna, 2004) that states that Latinos who develop relationships while in college and sustain old networks made in high school have a better opportunity of persisting in college. When students develop social capital as college students they are improving their chances at completing their college degree. If Pacific Northwest University wants to increase the retention of Latino students it should reinforce and expand programs such as ¡Éxito! and Freshman Inquiry.

\section{Academic Preparedness}


The majority of participants claimed they were dramatically unprepared for college coursework. They were shocked at the amount of work and reading required. Several stated that high school, even advanced placement courses, did not prepare them for the amount of reading required in college. Advanced placement courses are supposed to give high school students a sneak peek into what college will be like. If taking these courses in high school did not help students realize what college is actually like then, advanced placement courses are not achieving one of their primary purposes. This does not bode well for first-generation Latino students who may feel overwhelmed and could potentially drop-out if they are unaware of resources on campus to help them.

Fortunately, the ten Latinos of my study were given the tools and learned the resources available to them on the Pacific Northwest University campus. All ten participants participated in a college success course their first term their freshman year. This course taught them time management skills, budgeting skills, test taking tips, and other tools to help them succeed in their college career. Additionally, this course taught them the importance of and how to read their syllabi, which according to Collier and Morgan (2008) is something that traditional students take for granted. Their study found that first-generation students had difficulty with time-management and faculty expectations, the college success course these students were a part of addressed these concerns.

By taking this course, which is part of the ¡Éxito! Program, these students were aware of several resources on campus that are available to students. Most important among these resources are the writing center, the learning center where tutors are 
available, academic and general advising, and information on student organizations and clubs. These resources are vital to first-generation Latino students because many of them are in need of tutoring for math and sciences and a vast majority of them need help with their writing skills.

The participants of this study, with the exception of one or two, were not prepared for the workload or amount of reading that college requires. If it were not for the tools and resources or cultural capital that they learned from the ¡Éxito! Program, at least two of the students, Felicia and Rosa, explicitly mention that they might have dropped out of college. The importance of this program and what it teaches students who take part in it cannot be understated. Pacific Northwest University needs to take note of the Latinos who are recruited because of this outstanding program. In order to be successful college students, first-generation Latinos should be at the very least required to take some sort of college success course, perhaps while in high school. Such a course would prepare them for the college student role and what will be expected of them in terms of workload, reading, and faculty expectations. A course that provides students with the necessary resources and knowledge of how to fulfill the college student role by supplying them with cultural and social capital could be the difference between students persisting in college or dropping out. The Freshman Inquiry course and the ¡Éxito! Program both helped accomplish supplying students with cultural and social capital. These two programs helped students build community on campus, develop friendships, and helped them understand the college student role. They supplied cultural capital in the form of knowing how to speak to their professors and how to act during their college courses. These two 
programs supplied social capital to the students in this study by helping the students network and build relationships with other students but just as important with professors and university agents who will be able to pass on their knowledge of how to navigate university life. Future research needs to address the differences between first-generation students who take part in a college success course and those who do not. Perhaps the differences found between these two groups will persuade university officials to invest in programs that benefit first-generation programs such as ¡Éxito! and Freshman Inquiry. 


\section{REFERENCES}

Barajas, Heidi Lasley and Jennifer L. Pierce. 2001. "The Significance of Race and Gender in School Success among Latinas and Latinos in College." Gender and Society 15(6): 859-878.

Berg, Bruce L. 2009. Qualitative Research Methods. Boston, MA: Pearson.

Bohon, Stephanie A., Monica Kirkpatrick Johnson, and Bridget K. Gorman. 2006. "College Aspirations and Expectations among Latino Adolescents in the United States." Social Problems 53(2): 207-225.

Bourdieu, Pierre and Jean Claude Passeron. 1977. Reproduction in Education, Society, and Culture. Beverly Hills, CA: Sage.

Bourdieu, Pierre. 1986. “The Forms of Capital.” Pp. 241-258. In Handbook of Theory and Research for the Sociology of Education, edited by JG Richardson. New York: Greenwood.

Cammarota, Julio. 2004. "The Gendered and Racialized Pathways of Latino and Latino Youth: Different Struggles, Different Resistances in the Urban Context." Anthropology \& Education Quarterly 35(1): 53-74.

Ceja, Miguel. 2004. "Chicana College Aspirations and the Role of Parents: Developing Educational Resiliency. Journal of Hispanic Higher Education 3(4): 338-362.

Cerna, Oscar S., Patricia A. Perez, and Victor Sáenz. 2007. Examining the Pre-College Attributes and Values of Latina/o College Graduates. Higher Education Research Institute: UCLA. Retrieved June 10, 2013 from, http://www.heri.ucla.edu/PDFs/pubs/Reports/LatinoRetention_Report3.pdf 
Charmaz, Kathy. 2006. Constructing Grounded Theory: A Practical Guide Through Qualitative Analysis. Sage Publications.

Coleman, James S. 1988. "Social Capital in the Creation of Human Capital. American Journal of Sociology 94: S95-S120.

Collier, P.J., Fellows, C., \& Holland, B. 2008. "Students First: Improving First-Generation Student Retention and Performance in Higher Education: Final Report of Program Activities: 2005 - 2008” Report U.S. Department of Education, FIPSE Comprehensive Grant Program.

Collier, Peter J. and David L. Morgan. 2008. “'Is that paper really due today?’ Differences in First-Generation and Traditional College Students' Understanding of Faculty Expectations." Higher Education 55: 425-446.

Crosnoe, Robert, Lorena Lopez-Gonzalez and Chandra Muller. 2004. "Immigration from Mexico into the Math/Science Pipeline in American Education. Social Science Quarterly 85(5): $1208-1226$.

Desmond, Matthew and Ruth N. López Turley. 2009. "The Role of Familism in Explaining the Hispanic-White College Application Gap." Social Problems 56(2): 311-334.

Dumais, Susan A. 2002. "Cultural Capital, Gender, and School Success: The Role of Habitus." Sociology of Education 75(1): 44-68.

Facts on Hispanic Higher Education. 2000. The Voice, X, 14.

Gándara, Patricia. 2005. Fragile Futures: Risk and Vulnerability among Latino High Achievers. Princeton, NJ: Policy Information Center, Educational Testing Service (ETS). 
Hurtado, Sylvia, Deborah Faye Carter and Albert Spuler. 1996. "Latino Student Transition to College: Assessing Difficulties and Facters in Successful College Adjustment." Research in Higher Education 37(2): 135-157.

López, Nancy M. 2003. Hopeful Girls, Troubled Boys: Race and Gender Disparity in Urban Education. Albany: State of University of New York Press.

Marshall, Catherine and Gretchen B. Rossman. 2011. Designing Qualitative Research. Sage Publications.

Mead, Sara. 2006. The Evidence Suggests Otherwise: The Truth About Boys and Girls. Washington, DC: Education Sector.

Nappi, Rebcca. 2013. "First-generation Latino Students Making College a Family Affair.” The Spokesman Review. Retrieved June 10, 2013 from http://www.spokesman.com/stories/2013/mar/24/three-degrees-no-separation/

National Center for Education Statistics. 2005. Education Longitudinal Study of 2002:

Base-Year to First Follow-up Data File Documentation (NCES 2006-344).

Washington, DC: Author. Retrieved March 3, 2012, from

http://nces.ed.gov/pubsearch/pubsinfo.asp?pubid=2006344.

National Center for Education Statistics. 2005. "First-generation students in Postsecondary Education: A Look at Their College Transcripts." NCES 2005-17. National Conference of State Legislatures. 2011. "Improving Latino College Completion: What State Legislators Should Know.” NCSL 2011. Retrieved June 10, 2013, from http://www.ncsl.org/documents/educ/latinocollegecompletion.pdf 
Noddings, Nel. 1984. Caring: A Feminine Approach to Ethics and Moral Education. Berkeley: University of California Press.

Noddings, Nel. 1992. The Challenge to Care in Schools: An Alternative Approach to Education. New York: Teachers College Press.

Perez, Patricia and Patricia M. McDonough. 2008. "Understanding Latina and Latino College Choice: A Social Capital and Chain Migration Analysis." Journal of Hispanic Higher Education 7: 249-265.

Perna, Laura W. 2000. "Differences in the Decision to Attend College among African Americans, Hispanics, and Whites." The Journal of Higher Education 71(2): 117141

Perna, Laura W. and Marvin A. Titus. 2005. The Relationship between Parental Involvement as Social Capital and College Enrollment: An Examination of Racial/Ethnic Differences. The Journal of Higher Education 76(5): 485-518.

Portes, Alejandro. 1998. "Social Capital: Its Origins and Applications in Modern Sociology." Annual Review of Sociology 24: 1-24.

Reyes, Nicole Alia Salis and Amaury Nora. 2012. Lost Among the Data: A Review of Latino First Generation College Students. White paper prepared for the Hispanic Association of Colleges and Universities. Retrieved June 10, 2013 from http://www.hacu.net/images/hacu/OPAI/H3ERC/2012_papers/Reyes\%20nora\%2 0-\%20rev\%20of\%201st\%20gen\%20latino\%20college\%20students\%20\%202012.pdf 
Riegle-Crumb, Catherine. 2010. "More Girls go to College: Exploring the Social and Academic Factors Behind the Female Postsecondary Advantage Among Hispanic and White Students." Research in Higher Education 51: 573-593.

Saenz, Victor B. and Luis Ponjuan. 2009. "The Vanishing Latino Male in Higher Education." Journal of Hispanic Higher Education 8(1): 54-89.

Saenz, Victor B., Sylvia Hurtado, Doug Barrera, De'Sha Wolf, and Fanny Yeung. 2007. First In My Family: A Profile of First-Generation College Students at Four-Year Institutions Since 1971. Los Angeles: Higher Education Research Institute, UCLA.

Saunders, Marisa and Irene Serna. 2004. "Making College Happen: The College Experiences of First-Generation Latino Students." Journal of Hispanic Higher Education 3(2):146-163.

Somers, Patricia, Shawn Woodhouse, and Jim Cofer. 2004. "Pushing the Boulder Uphill: The Persistence of First-Generation College Students.” NASPA Journal 41(3) 418-435.

Stanton-Salazar, Ricardo and Sanford M. Dornbusch. 1995. "Social Capital and the Reproduction of Inequality: Information Networks among Mexican-origin High School Students." Sociology of Education 68: 116-135.

Strauss, Anselm and Juliet Corbin. 1998. Basics of Qualitative Research. Sage Publications.

Sy, Susan R. 2006. "Family and Work Influences on the Transition to College among Latina Adolescents." Hispanic Journal of Behavioral Sciences 28(3): 368-386. 
Thomas, Scott G. 2012. "Earnings Widen Between College and High School-Only Grads.” The Business Journals. Retrieved June 10, 2013 from http://www.bizjournals.com/bizjournals/on-numbers/scott-thomas/2012/12/gradsearn-85-more-than-those-without.html?page=all

Turley, Ruth N. López. 20006. "When Parents want Children to Stay Home for College." Research in Higher Education 47(7): 823-846.

Valenzuela, Angela. 1999. Subtractive Schooling: U.S.-Mexican Youth and the Politics of Caring. Albany: State of University of New York Press.

Zarate, Maria Estela and Ronald Gallimore. 2005. "Gender Differences in Factors Leading to College Enrollment: A Longitudinal Analysis of Latina and Latino Students." Harvard Educational Review 75(4): 383-408. 


\section{APPENDIX A: THE PARTICIPANTS}

\begin{tabular}{|l|l|l|l|l|}
\hline $\begin{array}{l}\text { Participant (In } \\
\text { order of } \\
\text { interview) }\end{array}$ & Gender & $\begin{array}{l}\text { Commute or } \\
\text { Lives on-campus }\end{array}$ & $\begin{array}{l}\text { Receiving } \\
\text { financial aid }\end{array}$ & $\begin{array}{l}\text { From the Urban- } \\
\text { Metropolitan area }\end{array}$ \\
\hline Participant 1 & Male & Commutes & Yes & Yes \\
\hline Participant 2 & Male & Commutes & Yes & Yes \\
\hline Participant 3 & Male & Commutes & Yes & No \\
\hline Participant 4 & Male & Commutes & Yes & Yes \\
\hline Participant 5 & Female & Commutes & Yes & Yes \\
\hline Participant 6 & Male & On-campus & Yes & No \\
\hline Participant 7 & Female & On-campus & Yes & No \\
\hline Participant 8 & Female & On-campus & Yes & No \\
\hline Participant 9 & Female & Commutes & Yes & Yes \\
\hline Participant 10 & Female & Commutes & Yes & Yes \\
\hline
\end{tabular}




\section{APPENDIX B: INTERVIEW GUIDE}

1. Before you came to Pacific Northwest University in the fall of 2011, what were your initial impressions of college? Probe: What did you think college was going to be like? Was it a shock when you first started or were you comfortable from the beginning?

2. What was your biggest fear when you started as a freshman here at PNU?

3. How many colleges did you apply to attend? Probe: If you only applied to Pacific Northwest University or one other college, why was that? Was it a financial issue with application fees or was there another reason?

4. Can you describe the process that led you to decide to attend college? Probe: Was there any particular person, people, or organization that motivated you to attend college? Follow-up: If that wasn't the case, do you think that you would have considered attending college? Why?

5. When did you know for certain that you would be attending PNU?

6. Do you believe that high school prepared you for college? In terms of the amount of work and studying that is involved?

7. How would you describe your experience here at Pacific Northwest University your freshmen year? Probe: Have you had an enjoyable experience, a miserable experience, or has your experience been something else? What are some things you know now that you wish you would have known when you began college?

8. Do you believe the PNU campus is an inviting and safe place for Latino/a students? Can you explain why you feel that way?

9. Did you ask professors if you had questions? Where did you go if you needed help with an assignment, a paper, or other class work?

How about your classmates in your freshman classes, did you get along with them?

10. How would you describe your adjustment here at Pacific Northwest University your freshmen year? Probe: Have you had difficulty adjusting from high school, have you adjusted well, or has your adjustment been something else?

11. Remembering your freshman year, what are some things that you know now about adjusting to college that you would tell a Latino/a high school student coming to PNU? Probe: What are the top two or three things that helped you make it through your freshman year? 
12. Can you describe any resources that have been helpful to you in your freshmen year at PNU? Probe: Are there any people, clubs, departments, or other things that have helped you adjust and have a good first-year experience? What is it about that resource specifically do you believe helped you the most?

13. If you would not have been involved with the ¡Éxito! Program and the college success course, do you think you would have had an enjoyable freshman year at PNU? Do you think you would have adjusted the same without these resources? Why or why not?

14. Being a Latino/a attending PNU, what would you say to encourage more Latinos to attend higher education? Probe: What do you think can be done to encourage more Latino males to attend college?

15. Why do you believe that more Latinas are attending college than Latino males?

16. Is there anything else that you would like to mention or maybe there is something you remembered that you think would be helpful to this research? 